\section{AB0450 DANISH PATIENTS WITH SYSTEMIC LUPUS ERYTHEMATOSUS SELF-REPORT HIGH LEVELS OF PHYSICAL ACTIVITY, AND MOST PATIENTS FULFILL THE WHO RECOMMENDATIONS ON PHYSICAL ACTIVITY}

M. Munch Beck ${ }^{1}$, S. Möller ${ }^{2}$, S. D. Kay ${ }^{1}$, A. Voss ${ }^{1} .{ }^{1}$ Odense University Hospital, Department of Rheumatology, Odense C, Denmark; ${ }^{2}$ OPEN - Open Patient data Explorative Network, Odense University Hospital, Department of Clinical Research, Odense, Denmark

Background: Physical activity is important for enhancing health and the World Health Organization (WHO) recommends that adults aged 18-64 engage in at leas 150 minutes of moderate-intensity physical activity throughout the week, or 75 minutes of vigorous-intensity physical activity (1). Swedish patients with SLE reported a lower frequency and capacity of exercise than a control group, and in an Italian study, $60 \%$ of the SLE patients did not meet WHO's recommendations for physical activity. Mental health is important for the individual's level of physical activity, and symptoms of depression have been associated with a lower level of physical activity in SLE patients (2).

Objectives: The aim of this study is to describe the pattern of physical activity in a population of Danish SLE patients, and to investigate the association to depression.

Methods: The study was conducted at the Department of Rheumatology at Odense University Hospital, Denmark, in 2018 and 2019. Two questionnaires were handed out before routine outpatient consultation: self-reported physical activity was evaluated using the International Physical Activity Questionnaire (IPAQ), and a continuous variable on energy requirement in the form of the metabolic equivalent (MET) was calculated, and the Major Depression Inventory (MDI) questionnaire was used to screen for depression. Medicine intake was registered, and disease activity and damage were scored using SLEDAI-2K and SLICC/ACR DI.

Results: Two hundred and fifteen patients completed the IPAQ and MDI, 5 were excluded. The population consist of $89.5 \%$ women and the mean age was $51.7 \pm$ 15.2 years. The mean disease duration was $16.1 \pm 10.1$ years.

The SLE patients reported a mean total MET-score of $5319.9 \pm 3650 \mathrm{MET}-\mathrm{min} /$ week. If divided into categories, $7.6 \%$ reported low level, $21.9 \%$ moderate and $70.5 \%$ of the patients reported a high level of physical activity and $89.5 \%$ fulfilled WHO recommendations. The participants reported $363.7 \pm 201$ minutes per day in sitting time.

Mean MDI score was $12.7 \pm 10.1$, and if divided into groups, $89.5 \%$ were not depressed, $1.9 \%$ had a mild depression, $5.3 \%$ had a moderate depression and $2.9 \%$ had a severe depression. Significantly lower mean MET-scores were observed for the severely depressed patients.

An inverse association was found in the univariate analysis, indication that increasing disease duration and SLICC/ACR DI scores were significantly associated with decreasing total MET-scores. In the multivariate analysis time spent sitting was inversely associated with MET-score.

Our results were similar to a Brazilian study, where $68 \%$ of the patients reported, that they were "physical active" according to IPAQ. In contrast, only $22 \%$ of the patients in an Italian study reported high level physical activity. Our proportion of active patients were high when comparing with studies on patients with rheumatoid arthritis and spondylarthritis, where only $25-50 \%$ fulfilled the WHO recommendations compared to our $89.5 \%$.

A Danish study on registered ICD diagnoses found a prevalence of depression in SLE patients to be $4.3 \%$, which was lower than our prevalence. Foreign studies reported very diverse prevalences of depression, e.g. $16.6 \%$ in the Netherlands and $51 \%$ in Sweden.

Conclusion: A high portion of the SLE patients reported a high level of physical activity and $89.5 \%$ fulfilled the WHO recommendations. Significant predictors for a lower level of physical activity were increasing disease duration, higher SLICC/ ACR DI score and longer time spent sitting. However, further studies are needed, where more suitable questionnaires could be considered.

References:

[1] WHO recommendations, Geneva 2010;60:1-58

[2] Gen Hosp Psychiatry. 2009;31:306-15.

Disclosure of Interests: None declared

DOI: 10.1136/annrheumdis-2020-eular.873

\section{AB0451 PRIMARY SJOGREN'S SYNDROME IN MEN}

S. Wafa ${ }^{1}$, A. Kefi' ${ }^{2}$, M. Ach ${ }^{2}$, F. Jaziri ${ }^{3}$, K. Ben Abdelghani², S. Turki ${ }^{2}$, T. Ben Abdallah ${ }^{2} .{ }^{1}$ Charles Nicole Hospital, Tunis, Internal Medicine, Tunis, Tunisia; ${ }^{2}$ Charles Nicole Hospital, Internal Medicine, Tunis, Tunisia; ${ }^{3}$ Djerba Regional Hospital, Internal Medicine, Djerba, Tunisia

Background: Primary Sjogren's syndrome (PSS) is characterized as an autoimmune exocrinopathy, but this disorder also may involve extraglandular organs, giving rise to multisystem disease. Although the first case reported by Dr Mikulicz was a 42 year old man [1], there are only few reports describing the clinical picture of Sjogren's Syndrome in males

Objectives: To determine whether there were any clinical and biological differences between male and female tunisian patients with primary Sjogren's syndrome (PSS)

Methods: We studied 60 patients with pSS according to American-European Consensus Group (AECG), attending an Internal Medicine departement in Tunisia. The nine (15\%) male patients in this cohort comprised the male group described in this study

Results: The average age of men at diagnosis was 53.2 years [ 31 to 73 years] Male SSp was revealed by sicca symptoms $(55.5 \%)$, by extra glandular manifestations (33.3\%). Fourty-four percent of our male patients had a positive result for a minor salivary gland biopsy (grade III or IV).

Extraglandular manifestations during the course of the disease were present in 6 cases $(66 \%)$ of our male patients with pSS. weight loss and raynaud's phenomenon were more common in men. a significantly greater percentage of men had neurological involvement $(66.6 \% \mathrm{vs} 23,7)$ and and pulmonary involvement, notably a restrictive syndrome ( $66.6 \%$ vs $31,1 \%, p=0.043)$. The positivity of Anti-nuclear antibodies, anti-SSb and rheumatoid factor were significantly less common in males.

Anemia was significanty more common in the male patients $(p=0,049)$. No cases of Lymphoma in the male patients in our series.

Eighty-eight percent of the men were treated with corticosteroids. In our series, the use of immunosuppressants was not necessary in male patients.

Conclusion: Although pSS is typically a disease affecting women, clinicians should be aware that it may be diagnosed in male patients. Although men were at the same risk for the development of extraglandular complications, there were significant serologic and immunogenetic differences. In Sharp contrast to women with Sjogren's syndrome, men with Sjogren's syndrome were more seronegative in our series.

References:

[1] Mikulicz J. Discussion at Verein fur wissenschaftliche Heilkunde zu königsberg. Berl Klin Wocchenschr 1888; 25:759.

[2] Gondran G, Fauchais A, Lambert M, Ly K, Launay D, Queyrel V, et al. Primary Sjogren's syndrome in men. Scandinavian journal of rheumatology. 2008;37(4):300-5.

[3] Virdee S, Greenan-Barrett J, Ciurtin C. A systematic review of primary Sjogren's syndrome in male and paediatric populations. 2017;36(10):2225-36

Disclosure of Interests: None declared

DOI: 10.1136/annrheumdis-2020-eular.5951

AB0452

PREDICTIVE FACTORS FOR INSUFFICIENT RESPONSE TO INITIAL TREATMENT OR RECURRENCE IN PATIENTS WITH LUPUS ENTERITIS

Y. Yoshida ${ }^{1}$, T. Sugimoto ${ }^{1}$, H. Kohno ${ }^{1}$, H. Watanabe ${ }^{1}$, S. Mokuda ${ }^{1}$, S. Hirata ${ }^{1}$, E. Sugiyama ${ }^{1}{ }^{1}$ Hiroshima University Hospital, Department of Clinical Immunology and Rheumatology, Hiroshima, Japan

Background: Lupus enteritis (LE) is a rare but well-known complication of systemic lupus erythematosus (SLE). However, little knowledge about risk factors for insufficient response to initial treatment or recurrence have been reported.

Objectives: To identify prognostic factors associated with poor response in patients with LE.

Methods: Patients diagnosed as having LE at our hospital were consecutively registered from January 2009 to October 2019. The diagnosis of LE was made according to the criteria of BILAG 2004 which is defined as either vasculitis or inflammation of small or large bowel with supportive imaging and/or biopsy findings. Poor response was defined as insufficient response to initial therapy or relapse. We retrospectively compared clinical characteristics collected from medical records of the patients with good vs. poor response, using a non-parametric Wilcoxon signed-rank test for numerical variables and Fisher's exact test for categorical variables.

Results: A total of 12 patients (16 episodes) diagnosed with LE were reviewed. The median age was 44.5 years and 11 were females. Six patients had a history of SLE (median disease duration; 3.0 years), of which 4 had a history of LE prior to the study period. And in the remaining 6 patients, LE was the primary symptom (Table 1). The comorbidities were 4 lupus cystitis, 1 biopsy-proven lupus nephritis, 1 pseudo-obstruction and 1 protein-losing enteropathy. Computed Tomography (CT) imaging of all 16 episodes showed small bowel wall thickening. Dilatation of intestine was observed in $81.3 \%$, ascites in $81.3 \%$, comb sign in $80.0 \%$ and target sign in $62.5 \%$. When comparing clinical characteristics between the groups revealed that $\mathrm{CT}$ findings were similar in both groups, however serum $\mathrm{CH} 50$ levels (median (interquartile ranges (IQR)) 37.2 (25.3-46.9) U/mL vs $17.6(7.1-21.4) \mathrm{U} / \mathrm{mL}$ $\mathrm{p}=0.0095)$ were significantly lower in poor response group. Furthermore, patients who initiated glucocorticoids (GCs) at a lower dose (less than or equal to $0.6 \mathrm{mg} /$ 
$\mathrm{kg}$ prednisolone equivalent dose (PEQ)) was significantly more frequent in poor response group (Table 2)

Table 1. Baseline demographics and outcomes of LE patients

\begin{tabular}{lcc}
\hline & Variables & $\mathrm{N}=12$ \\
Demographics & Female (\%) & 91.7 \\
& Age (yrs), median (IQR) & $44.5(34.0-47.5)$ \\
Baseline therapy & $3.0(0-9.0)$ \\
& SLE duration (yrs), median (IQR) & $7.0(0-10.5)$ \\
& Prednisolone (mg), median (IQR) & 16.7 \\
Cyclosporine (\%) & 8.3 \\
Outcomes & Azathioprine (\%) & 8.3 \\
& Mycophenolate mofetil (\%) & 8.3 \\
& Tacrolimus (\%) & $4.0(1.9-5.0)$ \\
& Follow-up period (yrs), median (IQR) & 33.3 \\
Poor response to initial therapy (\%) & 33.3 \\
Recurrence (\%) & 8.3 \\
& Need for surgical intervention (\%) & 0 \\
\hline
\end{tabular}

Table 2. Comparison of baseline characteristics and initial treatment between LE patients with good vs. poor response

\begin{tabular}{|c|c|c|c|c|}
\hline & Variables & $\begin{array}{l}\text { Good response } \\
\qquad(\mathrm{N}=10)\end{array}$ & $\begin{array}{c}\text { Poor response } \\
\qquad(\mathrm{N}=6)\end{array}$ & \\
\hline \multirow[t]{2}{*}{ Comorbidities } & Lupus cystitis (\%) & 30.0 & 33.3 & 1.0 \\
\hline & Lupus nephritis (\%) & 0 & 16.7 & 0.38 \\
\hline \multirow[t]{7}{*}{ CT findings } & Maximum external diameter & 30.8 & 25.3 & 0.083 \\
\hline & of small intestine $(\mathrm{mm})$, median (IQR) & $(22.2-37.9)$ & $(19.4-29.0)$ & \\
\hline & Colon involvement (\%) & 30.0 & 66.7 & 0.30 \\
\hline & Dilatation of intestine (\%) & 90.0 & 66.7 & 0.52 \\
\hline & Ascites (\%) & 90.0 & 66.7 & 0.52 \\
\hline & Comb sigr & 90.0 & 66.7 & 0.52 \\
\hline & Target sign $(\%)$ & 70.0 & 50.0 & 0.61 \\
\hline \multirow[t]{4}{*}{$\begin{array}{l}\text { Laboratory } \\
\text { findings }\end{array}$} & $\begin{array}{c}\text { anti-dsDNA Ab (IU/mL), median } \\
\text { (IQR) }\end{array}$ & $5.4(1.6-12.6)$ & $10.1(3.8-111.5)$ & 0.17 \\
\hline & CH50 (U/mL), median (IQR) & 37.2 & $17.6(7.1-21.4)$ & 0.009 \\
\hline & C4 (mg/dL), median (IQR) & $\begin{array}{c}(25.3-46.9) \\
16.0(10.5-27.3)\end{array}$ & 10.0 & 0.11 \\
\hline & C3 (mg/dL), median (IQR) & 66.0 & 46.5 & 0.10 \\
\hline \multirow[t]{2}{*}{$\begin{array}{l}\text { Initial } \\
\text { treatment }\end{array}$} & $\begin{array}{c}\text { Less than or equal to } 0.6 \mathrm{mg} / \mathrm{kg} \\
\text { PEQ (\%) } \\
\text { Intravenous cyclophosphamide }\end{array}$ & $\begin{array}{c}(56.8-79.8) \\
10.0\end{array}$ & $\begin{array}{c}(33.0-58.3) \\
\quad 66.7\end{array}$ & 0.036 \\
\hline & Intravenous cyclophosphamide & 10.0 & 16.7 & 1.0 \\
\hline
\end{tabular}

Conclusion: Lower level of $\mathrm{CH} 50$ and initial treatment with GCs at a lower dose were identified as prognostic factors associated with poor response to initial therapy or recurrence in LE.

Disclosure of Interests: : Yusuke Yoshida Grant/research support from: Astellas, Paid instructor for: Astellas, Tanabe Mitsubishi, Sanofi, Novartis, GlaxoSmithKline, Eli Lilly, Bristol-Myers Squibb, Chugai, Asahikasei, Eisai, Janssen, Speakers bureau: Astellas, Tanabe Mitsubishi, Sanofi, Novartis, GlaxoSmithKline, Eli Lilly, Bristol-Myers Squibb, Chugai, Asahikasei, Tomohiro Sugimoto: None declared, Hiroki Kohno: None declared, Hirofumi Watanabe: None declared, Sho Mokuda: None declared, Shintaro Hirata Grant/research support from: Eli Lilly, Consultant of: Bristol-Myers Squibb, UCB, Paid instructor for: AbbVie, Eisai, Tanabe-Mitsubishi, Speakers bureau: AbbVie, Eisai, Tanabe-Mitsubishi, Astellas, Ayumi, Bristol-Myers Squibb, UCB, Chugai, Eli Lilly, Janssen, Kissei, Sanofi, Takeda, Eiji Sugiyama Grant/research support from: AbbVie, Astellas, Ayumi, Kissei, Pfizer, Sanofi, Takeda, Tanabe-Mitsubishi, Bristol-Myers Squibb, Chugai, Eisai, Eli Lilly, Speakers bureau: AbbVie, Astellas, Ayumi, Kissei, Pfizer, Sanofi, Takeda, Tanabe-Mitsubishi, Bristol-Myers Squibb, Chugai, Eisai, Eli Lilly, Actelion DOI: 10.1136/annrheumdis-2020-eular.1596

\section{AB0453 CORONARY ARTERY DISEASES IN PATIENTS WITH ANTIPHOSPHOLIPID ANTIBODY SYNDROME: A RETROSPECTIVE COHORT STUDY IN CHINA}

S. Zhang ${ }^{1}$, L. Wang ${ }^{2}$, Z. Shen ${ }^{2}$, S. Zhang ${ }^{2}$, M. Li ${ }^{1}{ }^{1}$ Peking Union Medical College Hospital, Peking Union Medical College and Chinese Academy of Medical Sciences, Rheumatology, Beijing, China; ${ }^{2}$ Peking Union Medical College Hospital, Peking Union Medical College and Chinese Academy of Medical Sciences, Cardiology, Beijing, China

Background: Antiphospholipid syndrome (APS) is an autoimmune disorder caused by pathogenic antiphospholipid antibodies. Coronary artery disease as one of cardiac involvement of APS brings great challenges in clinical practice.

Objectives: To identify the key demographic, clinical, angiography features, risk factors, and prognosis of patients presenting with coronary artery diseases in APS. Methods: We retrospectively analyzed patients who had been diagnosed with coronary artery disease induced by APS between January $1^{\text {st }}, 2012$ and June $30^{\text {th }}, 2019$, to study the clinical features, management, risk factors for prognosis, and long-term outcomes of patients.
Results: Twenty-eight patients (50\% female) with APS and coronary artery diseases were included, with average age $46.9 \pm 14.4$ years. Arterial thrombosis events $(78.6 \%, n=22)$ were more common than venous events $(42.9 \%, n=12)$ in this cohort. Twelve patients had stable CAD, while 14 patients had acute coronary syndrome. The most affected arteries were the anterior descending $(60.9 \%)$, right coronary $(39.1 \%)$, and circumflex $(30.4 \%)$. More RCA stenosis $(63.6 \%$ vs $16.7 \%$, $\mathrm{p}=0.036$ ) were observed in the primary APS group than in the secondary APS. The age and disease duration of patients differed among groups and was lower in the triple aPL positive group than in double- and single-aPL positive groups, withou significant differences among different CAD manifestations. Thrombocytopenia elevated creatinine, and elevated urea were the risk factors for poor prognosis. Conclusion: The coronary artery is an important target organ for APS. More RCA stenosis were observed in the primary APS group. APS-related CAD could endanger life and increase the mortality rate, with risk factors of thrombocytopenia, elevated creatinine, and elevated urea level. In addition to the routine use of anticoagulant and antiplatelet drugs, management of this group of patients is not well documented. The best treatment strategy still needs to be found and evaluated.

\section{References:}

[1] Mavrogeni SI, Sfikakis PP, Kitas GD, Kolovou G, Tektonidou MG. Cardiac involvement in antiphospholipid syndrome: The diagnostic role of noninvasive cardiac imaging. Semin Arthritis Rheum. 2016;45(5):611-616.

[2] Denas G, Jose SP, Bracco A, Zoppellaro G, Pengo V. Antiphospholipid syndrome and the heart: A case series and literature review. Autoimmun Rev. 2015;14(3):214-222.

[3] Cervera R, Piette JC, Font J, et al. Antiphospholipid syndrome: Clinical and immunologic manifestations and patterns of disease expression in a cohort of 1,000 patients. Arthritis Rheum. 2002;46(4):1019-1027.

Table 1. Coronary artery disease assessment of the patients

\begin{tabular}{|c|c|c|c|c|}
\hline & Total & Types of APS & & \\
\hline & & $\begin{array}{l}\text { pAPS } \\
(n=13)\end{array}$ & $\begin{array}{l}\text { SAPS } \\
(n=15)\end{array}$ & $\mathbf{p}$ \\
\hline \multicolumn{5}{|l|}{ Coronary artery diseases } \\
\hline $\operatorname{sCAD}(n, \%)$ & $12,42.9$ & $6,46.2$ & $6,40.0$ & .743 \\
\hline UA $(n, \%)$ & $2,7.1$ & $1,7.7$ & $1,6.7$ & 1.0 \\
\hline NSTEMI (n, \%) & $5,17.9$ & $4,30.8$ & $1,6.7$ & .153 \\
\hline STEMI (n, \%) & $7,25.0$ & $2,15.4$ & $5,33.3$ & .396 \\
\hline Other (n, \%) & $2,7.1$ & 0,0 & $2,13.3$ & .484 \\
\hline Coronary artery thrombosis & $17,60.7$ & $8,61.5$ & $9,60.0$ & .934 \\
\hline $\mathrm{ECHO}(\mathbf{n})$ & 26 & 13 & 13 & \\
\hline LVEF (\%) & $52.2 \pm 15.0$ & $46.8 \pm 12.0$ & $57.6 \pm 15.7$ & .09 \\
\hline Segmental ventricular wall motion abnormality & $21,80.8$ & $11,84.6$ & $10,76.9$ & 1.00 \\
\hline Diastolic dysfunction & $11,42.3$ & $5,38.4$ & $6,46.1$ & 1.00 \\
\hline Ventricular enlargement & $13,50.0$ & $7,53.8$ & $6,46.1$ & 1.00 \\
\hline Atrial enlargement & $14,53.8$ & 7, 53.4 & $7,53.4$ & 1.04 \\
\hline CAG or CTA performance $(n)$ & 23 & 11 & 12 & \\
\hline LM stenosis $(\mathrm{n}, \%)$ & $5,21.7$ & $3,27.3$ & $2,16.7$ & .640 \\
\hline LAD stenosis (n, \%) & $14,60.9$ & $6,54.5$ & $8,66.7$ & .680 \\
\hline LCX stenosis (n, \%) & 7, 30.4 & $3,27.3$ & $4,33.3$ & 1.00 \\
\hline RCA stenosis (n, \%) & $9,39.1$ & $7,63.6$ & $2,16.7$ & .036 \\
\hline aneurysm $(n, \%)$ & $1,4.3$ & 0,0 & $1,8.3$ & 1.00 \\
\hline
\end{tabular}

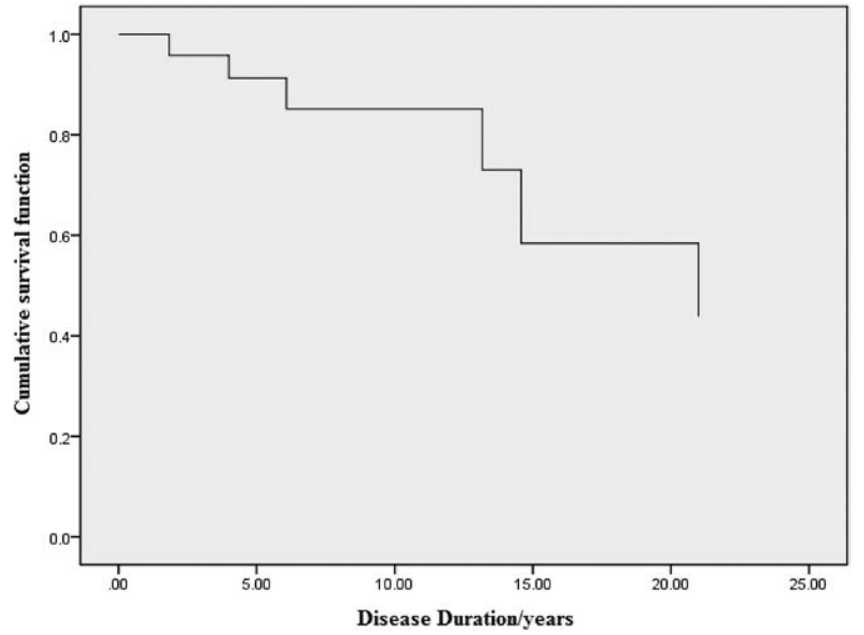

Figure 1. Cumulative survival function figure in APS patients with CAD

Disclosure of Interests: : None declared

DOI: 10.1136/annrheumdis-2020-eular.920 